\title{
Bacillus subtilis 6S-2 RNA serves as a template for short transcripts in vivo
}

\author{
PHILIPP G. HOCH, ${ }^{1}$ JULIA SCHLERETH, ${ }^{1}$ MARCUS LECHNER, and ROLAND K. HARTMANN \\ Institut für Pharmazeutische Chemie, Philipps-Universität Marburg, 35037 Marburg, Germany
}

\begin{abstract}
The global transcriptional regulator 6S RNA is abundant in a broad range of bacteria. The RNA competes with DNA promoters for binding to the housekeeping RNA polymerase (RNAP) holoenzyme. When bound to RNAP, 6S RNA serves as a transcription template for RNAP in an RNA-dependent RNA polymerization reaction. The resulting short RNA transcripts (so-called product RNAs $=$ pRNAs) can induce a stable structural rearrangement of $6 S$ RNA when reaching a certain length. This rearrangement leads to the release of RNAP and thus the recovery of transcription at DNA promoters. While most bacteria express a single $6 \mathrm{~S}$ RNA, some harbor a second 6S RNA homolog (termed 6S-2 RNA in Bacillus subtilis). Bacillus subtilis 6S-2 RNA was recently shown to exhibit essentially all hallmark features of a bona fide 6S RNA in vitro, but evidence for the synthesis of 6S-2 RNAderived pRNAs in vivo has been lacking so far. This raised the question of whether the block of RNAP by 6S-2 RNA might be lifted by a mechanism other than pRNA synthesis. However, here we demonstrate that 6S-2 RNA is able to serve as a template for pRNA synthesis in vivo. We verify this finding by using three independent approaches including a novel primer extension assay. Thus, we demonstrate the first example of an organism that expresses two distinct 6S RNAs that both exhibit all mechanistic features defined for this type of regulatory RNA.
\end{abstract}

Keywords: 6S RNA; 6S-1 RNA; bsrA; 6S-2 RNA; bsrB; pRNA; product RNA; RNA-seq; Northern blot; primer extension

\section{INTRODUCTION}

6S RNA is a small noncoding RNA involved in transcriptional regulation in bacteria (Wassarman and Storz 2000; Wehner et al. 2014). It binds to the housekeeping RNA polymerase (RNAP) holoenzyme by mimicking an open promoter structure (Wassarman 2002; Barrick et al. 2005). Escherichia coli 6S RNA reaches its highest cellular levels when cells enter stationary growth, where the RNA is thought to contribute to the economical utilization of nutrients and metabolites (Cavanagh and Wassarman 2013; for review, see Steuten et al. 2014). Most bacteria have a single 6S RNA, such as E. coli, where the function of 6S RNA as a transcriptional regulator was first described (Wassarman and Storz 2000). In contrast, some species were reported to harbor two or even more 6S RNA homologs (Wehner et al. 2014), among them Bacillus subtilis expressing 6S-1 (bsrA) and 6S-2 (bsrB) RNA (Ando et al. 2002; Suzuma et al. 2002; Barrick et al. 2005; Trotochaud and Wassarman 2005). At present, the regulatory role of the paralogous $6 \mathrm{~S}-2$ RNA is poorly understood. While 6S-1 RNA levels peak upon entry into stationary phase, 6S-2 RNA was reported to reach highest

\footnotetext{
${ }^{1}$ Joint first authors

Corresponding authors: roland.hartmann@staff.uni-marburg.de, lechner@staff.uni-marburg.de

Article published online ahead of print. Article and publication date are at http://www.rnajournal.org/cgi/doi/10.1261/rna.055616.115.
}

steady-state levels between early and mid-exponential phase. Its levels were described to either decrease toward stationary phase (Ando et al. 2002; Barrick et al. 2005; Beckmann et al. 2011) or to remain largely constant over the entire growth period (Trotochaud and Wassarman 2005; Cavanagh et al. 2012), possibly depending on the strain background (Steuten et al. 2014).

While bound to 6S RNA, RNAP is able to use 6S RNA as a template for transcription of so-called product RNAs (pRNAs) in an RNA-dependent RNA polymerization reaction (Wassarman and Saecker 2006). For 6S-1 RNA, thought to be the canonical 6S RNA in B. subtilis, RNA-seq of stationary phase cells combined with pRNA in vitro transcription analyses identified pRNAs with a length of 8-9 nt to be abundant; pRNAs shorter than $8 \mathrm{nt}$ are detectable in vitro as well (Beckmann et al. 2011, 2012; Burenina et al. 2014), but their abundance in vivo could not be assessed owing to uncertain assignment of such short reads to the 6S-1 RNA locus. Upon nutritional upshift when stationary cells reenter exponential growth, the total number of pRNA transcripts and

(c) 2016 Hoch et al. This article is distributed exclusively by the RNA Society for the first 12 months after the full-issue publication date (see http:// rnajournal.cshlp.org/site/misc/terms.xhtml). After 12 months, it is available under a Creative Commons License (Attribution-NonCommercial 4.0 International), as described at http://creativecommons.org/licenses/by-nc/ $4.0 /$ 
particularly the fraction of longer pRNAs $(\geq 14 \mathrm{nt})$ were found to increase (Beckmann et al. 2011, 2012). While shorter pRNAs (approximately $<10 \mathrm{nt}$ ) are thought to be abortive transcripts that dissociate from 6S-1 RNA during idling cycles of abortive transcription (Beckmann et al. 2012), longer pRNAs remain stably bound and are able to cotranscriptionally induce a rearrangement of the 6S-1 RNA structure. The resulting structural change of 6S-1 RNA then triggers the release of RNAP from its sequestration (Wassarman and Saecker 2006; Beckmann et al. 2012). Subsequently the released and now accessible 6S-1 RNA:pRNA hybrid is assumed to be degraded, possibly initiated by endonucleolytic cleavage in the apical loop of 6S-1 RNA (Beckmann et al. 2011).

Bacillus subtilis 6S-2 RNA has been studied as well in recent years and was shown to possess all hallmark features of a bona fide 6S RNA in vitro, including the ability to serve as a template for pRNA transcription (Supplemental Fig. S1; Burenina et al. 2014). However, previous 454 RNA-seq and Northern blot analyses failed to prove the presence of $6 \mathrm{~S}-2$ RNA-derived pRNAs in RNA fractions extracted from $B$. subtilis cells (Beckmann et al. 2011; Cavanagh et al. 2012). This may be attributed to the fact that $B$. subtilis RNAP initiates 6S-2 pRNA synthesis with ATP (Beckmann et al. 2011), which is less efficient than 6S-1 pRNA initiation with GTP (Cabrera-Ostertag et al. 2013). These findings fostered the idea that 6S-2 RNA may not serve as a template for pRNA synthesis under physiological conditions (Cavanagh et al. 2012; CabreraOstertag et al. 2013), raising the question how 6S-2 RNA might be displaced from RNAP in vivo.

We demonstrate here, for the first time, that 6S-2 RNA-derived pRNAs are produced in substantial amounts during exponential growth in vivo. This was proven by three independent experimental approaches: (i) RNA-seq of cellular RNA extracts enriched for short primary transcripts using Illumina technology to obtain high read numbers, (ii) application of a Northern blot procedure with RNA fractions prepared by the TRIzol method for efficient extraction of small RNAs (Damm et al. 2015), combined with a probe that confers enhanced detection sensitivity, and (iii) a novel primer extension assay which utilizes the 6S-2 pRNAs as primers on a complementary DNA template. The novel insight gained here indicates that 6S-2 RNA is a fully functional $6 \mathrm{~S}$ RNA homolog with the ability to inhibit RNAP activity and to release RNAP from its sequestration by serving as a template for pRNA synthesis analogous to 6S-1 RNA. However, regulation of the $\sigma^{\mathrm{A}}$-RNAP holoenzyme by $6 \mathrm{~S}-2$ RNA seems to be less dynamic than the enzyme's functional interplay with 6S-1 RNA.

\section{RESULTS}

\section{S-2 pRNAs are detectable by Illumina-based RNA-seq}

So far, 6S-2 RNA-derived pRNAs could not be detected in B. subtilis, neither by 454 RNA-seq nor by Northern blotting (Beckmann et al. 2011; Cavanagh et al. 2012). However, here we show that 6S-2 RNA-derived pRNAs are observable in libraries enriched for small primary transcripts $(<50 \mathrm{nt}$; Table 1) when using Illumina-based RNA-seq. We also included B. subtilis 6S RNA deletion strains in this analysis to verify the specific nature of pRNA reads. The parental B. subtilis PY79 strain is termed wild type (wt), and the respective deletion strains are abbreviated as $\triangle b s r A$ (deletion of the $6 \mathrm{~S}-1$ RNA gene), $\Delta b s r B$ (deletion of the 6S-2 RNA gene),

TABLE 1. Overview of the pRNA length species identified by RNA-seq in wild type (wt) and deletion/complementation strains $\triangle b s r A(\triangle \mathrm{A}), \Delta b s r B(\triangle \mathrm{B}), \Delta b s r A B(\triangle \mathrm{AB}), \Delta b s r A B+A$ $(\triangle A B+A)$, and $\triangle \mathrm{bsr} A B+B(\triangle A B+B)$ for $6 S-1$ RNA-derived pRNAs (upper part) and $6 \mathrm{~S}-2$ RNA-derived pRNAs (lower part).

\begin{tabular}{|c|c|c|c|c|c|c|c|c|c|c|c|c|c|}
\hline \multicolumn{7}{|c|}{ exponential } & \multicolumn{3}{|l|}{ 6S-1 pRNA } & \multicolumn{3}{|c|}{ stationary } & \multirow[b]{2}{*}{$15^{3 x^{60}}$} \\
\hline [nt] & 3 & 8 & 8 & $8^{3}$ & $18^{3 x^{x+}}$ & $8^{3 x^{x}}$ & \multirow{2}{*}{ 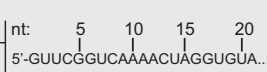 } & 3 & 8 & 8 & $8^{8}$ & 18 & \\
\hline $22-25$ & - & - & 6 & - & 3 & - & & 6 & - & 4 & - & 8 & - \\
\hline 20-21 & 7 & - & 13 & - & 19 & - & 5-GUUCGGUCAAAACUAGGUGU(A) & 5 & - & 4 & - & 8 & - \\
\hline 19 & 11 & - & 26 & - & 14 & - & 5'GUUCGGUCAAAACUAGGUG & 40 & - & 16 & - & 85 & - \\
\hline 18 & 6 & - & 57 & - & 65 & - & 5'-GUUCGGUCAAAACUAGGU & 75 & - & 64 & - & 239 & - \\
\hline 17 & 6 & - & 49 & - & 49 & 1 & 5'-GUUCGGUCAAAACUAGG & 51 & - & 62 & - & 193 & - \\
\hline 16 & 12 & - & 20 & - & 49 & - & 5'-GUUCGGUCAAAACUAG & 42 & - & 369 & - & 499 & 1 \\
\hline $14-15$ & 43 & 2 & 115 & - & 306 & 1 & 5'-GUUCGGUCAAAACU(A) & 664 & - & 8393 & 5 & 6274 & - \\
\hline 13 & 34 & - & 146 & 4 & 373 & - & 5'-GUUCGGUCAAAAC & 595 & 1 & 13446 & 8 & 5316 & - \\
\hline 8-12 & 1392 & 2 & 13906 & 42 & 27008 & 3 & 5'-GUUCGGUC(AAAA) & 4903 & 2 & 187316 & 190 & 47591 & 5 \\
\hline \multirow[t]{4}{*}{7} & 792 & 0 & 2019 & 10 & 3654 & 10 & 5'-GUUCGGU & \begin{tabular}{|l|}
317 \\
\end{tabular} & 1 & 22861 & 23 & 5398 & 1 \\
\hline & 2303 & 4 & 16357 & 56 & 31540 & 15 & \multirow{3}{*}{$\begin{aligned} & \sum \mathrm{pRNA}_{\mathrm{sS}-1} \text { reads } \geq 7 \mathrm{nt} \\
& \% \mathrm{pRNA}_{\mathrm{ss}-1} \text { reads } \geq 7 \mathrm{nt} \\
& 6 \mathrm{~S}-2 \mathrm{pRNA}\end{aligned}$} & 6698 & 4 & 232535 & 226 & 65611 & 7 \\
\hline & 0.110 & $<0.001$ & 1.995 & $\mid 0.007$ & 3.820 & 0.002 & & 0.300 & $<0.001$ & 27.357 & 0.024 & 7.427 & $<0.001$ \\
\hline & $x$ & 8 & $\beta$ & 3 & $a^{3 x^{x^{x}}}$ & $3^{38^{80}}$ & & & 8 & 8 & 8 & $8^{3 x^{x}}$ & $30^{3^{8}}$ \\
\hline $28-41$ & 24 & 2 & - & - & - & 22 & $\begin{array}{lrrr}\text { nt: } & 5 & 10 & 15 \\
& 1 & 1 \\
5 \text {-AAAGGUAAAACUUAAU... }\end{array}$ & 22 & 53 & - & - & - & 103 \\
\hline 17 & - & - & - & - & - & 1 & 5-AAAGGUUAAAACUUAAU & - & - & - & - & - & - \\
\hline $4-16$ & 17 & 11 & - & - & - & - & 5-AAAGGUUAAAACUU(AA) & 2 & - & - & - & - & 1 \\
\hline 13 & 44 & 79 & - & - & - & 5 & 5-AAAGGUUAAAACU & - & - & - & - & - & 4 \\
\hline 12 & 178 & 267 & - & - & - & 17 & 5'AAAGGUUAAAAC & 2 & 12 & - & - & - & 27 \\
\hline 7-11 & \begin{tabular}{|c|}
1815 \\
\end{tabular} & 2366 & - & - & - & 256 & 5-AAAGGUU(AAAA) & 20 & 28 & - & - & - & 84 \\
\hline & \begin{tabular}{|l|}
2078 \\
\end{tabular} & \begin{tabular}{|l|}
2725 \\
\end{tabular} & 0 & 0 & 0 & 301 & $\sum \mathrm{pRNA}_{\mathrm{BS} 2}$ reads $\geq 7 \mathrm{nt}$ & 46 & 93 & 0 & 0 & 0 & 219 \\
\hline & 21.098 & $\begin{array}{l}0.290 \\
9.3 \mathrm{M}\end{array}$ & $8.2 \mathrm{M}$ & $8.4 \mathrm{M}$ & $83 \mathrm{M}$ & 0.031 & $\% o$ pRN & $\begin{array}{l}0.002 \\
224 \mathrm{M}\end{array}$ & $\begin{array}{ll}0.004 \\
223 & 3 \mathrm{M}\end{array}$ & $85 \mathrm{M}$ & $93 \mathrm{M}$ & $8.8 \mathrm{M}$ & $\begin{array}{l}0.070 \\
209 \mathrm{M}\end{array}$ \\
\hline & $26.9 \mathrm{M}$ & & $8.6 \mathrm{M}$ & $8.8 \mathrm{M}$ & $8.7 \mathrm{M}$ & $20.9 \mathrm{M}$ & total reads & $23.3 \mathrm{M}$ & $24.2 \mathrm{M}$ & $8.8 \mathrm{M}$ & $10.0 \mathrm{M}$ & $9.3 \mathrm{M}$ & $23.6 \mathrm{M}$ \\
\hline
\end{tabular}

Note that the numbers of total reads in the last two rows are rounded, while the exact read numbers were used to calculate the numbers above bars in Figure $1 ; \mathrm{M}$, million; nt, nucleotide(s); 3 '-terminal A residues of pRNAs in parentheses: 3 '-terminal A residues could not be unequivocally assigned to the respective pRNAs because poly(A)-tailing was used for library construction. (Exponential) RNA extracted from cells at $\mathrm{OD}_{600}=0.9$; (stationary) RNA extracted from cells at $\mathrm{OD}_{600}=7$ (before death phase). 
$\triangle b s r A B(\triangle b s r A / \triangle b s r B$, deletion of both 6S RNA genes), $\triangle b s r A B+A$ (bsrA reintegrated into the $\triangle b s r A B$ strain at the $a m y E$ locus under control of the native 6S-1 RNA gene promoter), and $\triangle b s r A B+B$ (bsrB reintegrated into the $\triangle b s r A B$ strain at the amyE locus under control of the native $6 \mathrm{~S}-2$ RNA gene promoter) (Hoch et al. 2015). 6S-2 RNA-derived pRNA reads were exclusively detected in strains expressing 6S-2 RNA (wt, $\triangle b s r A$ and $\triangle b s r A B+B$ ), but not in those with a deletion of the $b s r B$ gene $(\triangle b s r B$ and $\triangle b s r A B+A$; Table 1; Fig. 1A). This finding verified that the detected reads indeed represent genuine 6S-2 pRNAs. Based on the library from exponentially growing wt cells (Table 1 , first column on the left), it appears that roughly equal numbers of 6S-1 and 6S-2 pRNAs are synthesized in this growth phase. Moreover, 6S-2 pRNAs were much more abundant in libraries of cellular RNA prepared from exponentially growing cells relative to RNA preparations from stationary phase cells. This is in line with 6S-2 RNA levels being higher in exponential than stationary phase and with the presence of low levels of the rivaling 6S-1 RNA during exponential growth (Ando et al. 2002; Barrick et al. 2005; Beckmann et al. 2011).

With respect to $6 \mathrm{~S}-1$ pRNA reads, substantial read numbers were also linked to the presence of the $b s r A$ gene encoding 6S-1 RNA (Table 1). In line with our previous 454 RNA-seq analysis (Beckmann et al. 2011), pRNAs $\leq 12$ nt prevailed and more reads were identified in libraries from stationary relative to exponential phase cells, consistent with 6S-1 RNA levels peaking toward stationary phase (Ando et al. 2002; Barrick et al. 2005; Beckmann et al. 2011). Interestingly, the fraction of $6 \mathrm{~S}$ RNA-derived very long transcripts (including runoffs in the case of 6S-2 pRNAs) was higher for 6S-2 than 6S-1 RNA, and this was even more pronounced for stationary cells. The lack of any 6S-1 pRNA runoffs (40-mers) may not necessarily indicate their lack of synthesis, as they might not have entered the cDNA libraries owing to resisting dissociation of 6S-1 RNA:pRNA hybrids because of increased duplex stability ( $\sim 43 \%$ G/C of $6 S-1$ runoffs relative to $\sim 29 \% \mathrm{G} / \mathrm{C}$ of $6 \mathrm{~S}-2$ runoffs).

Compared with the wt strain, more $6 \mathrm{~S}-1$ pRNA reads were detected in libraries from strains lacking 6S-2 RNA (illustrated in Fig. 1B). This difference gains even more weight when considering that the wt libraries had the highest total numbers of reads (Table 1). A similar but less pronounced and not fully consistent trend was seen for 6S-2 pRNA reads in $b s r A$ deletion strains relative to the wt strain (Table 1; Fig. 1B; see Discussion).

\section{S-2 pRNAs are detectable by Northern blotting}

In a preceding study (Beckmann et al. 2010) we succeeded in visualizing very small RNA species ( $\sim 14 \mathrm{nt})$ by Northern blotting, combining (i) the highly efficient EDC [1-ethyl3-(3-dimethylaminopropyl)carbodiimide hydrochloride] crosslinking for immobilization of short RNAs on nylon membranes (Pall et al. 2007), (ii) 5'-digoxigenin-labeled

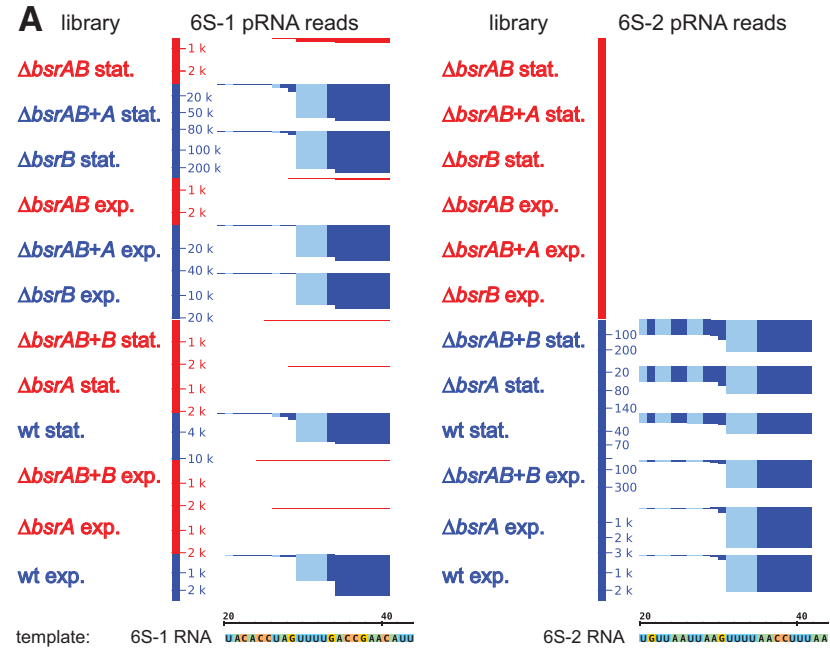

B

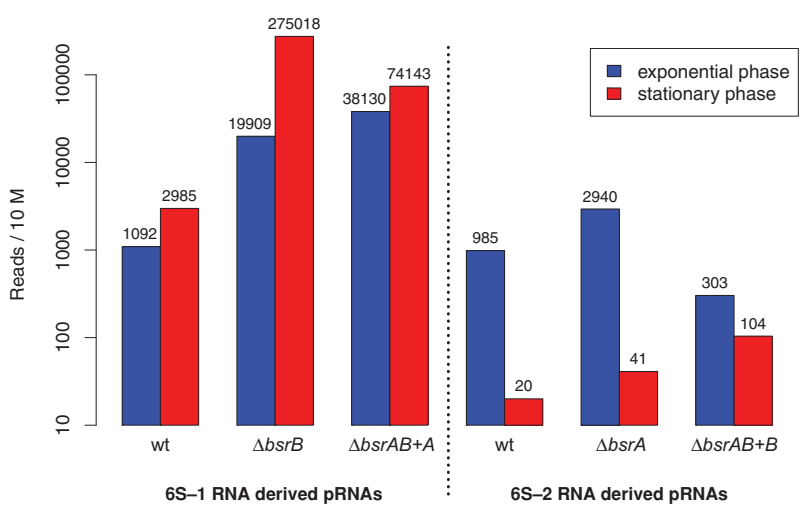

FIGURE 1. (A) cDNA reads mapping antisense to 6S-1 RNA (left) and 6S-2 RNA (right) visualized using the Integrated Genome Browser (IGB). (Red) No reads expected because the corresponding 6S RNA gene is deleted; (blue): reads expected due to the presence of the corresponding 6S RNA gene. $3^{\prime}$-terminal A residues could not be unequivocally assigned to the respective pRNAs because poly $(\mathrm{A})$-tailing was used for library construction; since these A residues were nevertheless included in the mapping, we have marked those positional coverages in light blue. RNAs extracted from the following strains were analyzed: wt, the parental B. subtilis PY79 strain; $\triangle b s r A ; \triangle b s r B ; \triangle b s r A B(\Delta b s r A / \Delta b s r B)$; $\triangle b s r A B+A, b s r A$ reintegrated into the $\triangle b s r A B$ strain at the amyE locus under control of the native 6S-1 RNA gene promoter; $\triangle b s r A B+B, b s r B$ reintegrated into the $\triangle b s r A B$ strain at the amyE locus under control of the native 6S-2 RNA gene promoter; exp., RNA extracted from exponentially growing cells at $\mathrm{OD}_{600}=0.9$; stat., RNA extracted from stationary cells at $\mathrm{OD}_{600}=7$ (before death phase). For more details, see text. Canonical pRNAs were found in all strains expressing the respective $6 \mathrm{~S}$ RNA, but not (or at least in negligible amounts) whenever the gene was deleted, indicating that these are actually 6S RNA-templated pRNA transcripts. (B) Normalized read levels (per 10 million reads $\geq$ $7 \mathrm{nt}$ ) of 6S-1 and 6S-2 RNA-derived pRNAs in exponential and stationary growth phase on a logarithmic scale. Example calculation to illustrate how we arrived at the read numbers: for "wt exponential, 6S-1 pRNAs" in Table 1, we had 21,086,349 sequence reads after filtering, which were rounded to $21.0 \mathrm{M}$ in Table 1 . We then divided the number of 6 S- 1 pRNA reads (2303) by $21,086,349$ and multiplied with $10 \mathrm{M}$ to normalize the pRNA reads to the total number of reads: 2303/ $21,086,349 \times 10,000,000=1092.18$ (rounded to 1092 ) reads per $10 \mathrm{M}$ reads. 
probes containing DNA and a few locked nucleic acid (LNA) (Vester and Wengel 2004) residues-which increase affinity for complementary sequences-and (iii) native PAA gel systems to avoid EDC reaction with the amino groups of the urea denaturant instead of the primary amino groups of the membrane. Although 6S-1 pRNAs were detected with this technique (Beckmann et al. 2010), a detection of 6S-2 pRNAs was unsuccessful so far (RK Hartmann, unpubl.). With the following modifications we were able to detect 6S-2 pRNAs (Fig. 2): We used RNA/LNA mixmer probes with a high LNA content (up to 10 out of $14 \mathrm{nt}$ ), a double digoxigenin label at the $5^{\prime}$ - and $3^{\prime}$-end (to increase signal intensity), and applied the TRIzol RNA extraction method to enrich for small RNAs (Damm et al. 2015). In Northern blots of the type shown in Figure 2B, we detected signals for 6S-2 pRNAs in the range of 14-25 nt for RNA preparations from wt and $\triangle b s r A$ bacteria, but not for those originating from $\triangle b s r B$ and $\triangle b s r A B$ bacteria lacking the 6S-2 RNA gene. This indicates that the signals in lanes 1 and 2 of Figure $2 \mathrm{~B}$ in the size range below $\sim 25 \mathrm{nt}$ indeed represent genuine $6 \mathrm{~S}-2$ pRNAs. The main pRNA signals in lanes 1 and 2 in Figure
$2 \mathrm{~B}$ represent a higher length range compared with the pRNA length distribution in Table 1 (6S-2 pRNA reads for the wt and $\Delta b s r A$ strain in exponential phase). An explanation could be the decreasing Northern blot detection efficiency at decreasing pRNA length.

\section{Detection of 6S-2 pRNAs by a primer extension assay}

For detection of 6S-2 pRNAs in total cellular RNA, we developed a novel primer extension-based approach. The central idea was to detect $6 \mathrm{~S}-2$ pRNAs via their ability to function as RNA primers in a primer extension reaction (see scheme in Fig. 3A). For this purpose, we designed a DNA oligonucleotide complementary to 6S-2 pRNAs in its $3^{\prime}$-portion (the $3^{\prime}$ terminal DNA nucleotide matching the initiating pRNA nucleotide). All pRNA length variants up to the 41-nt runoff pRNA transcript could potentially anneal to this oligonucleotide. After addition of radiolabeled dNTPs and Avian Myeloblastosis Virus (AMV) reverse transcriptase, which
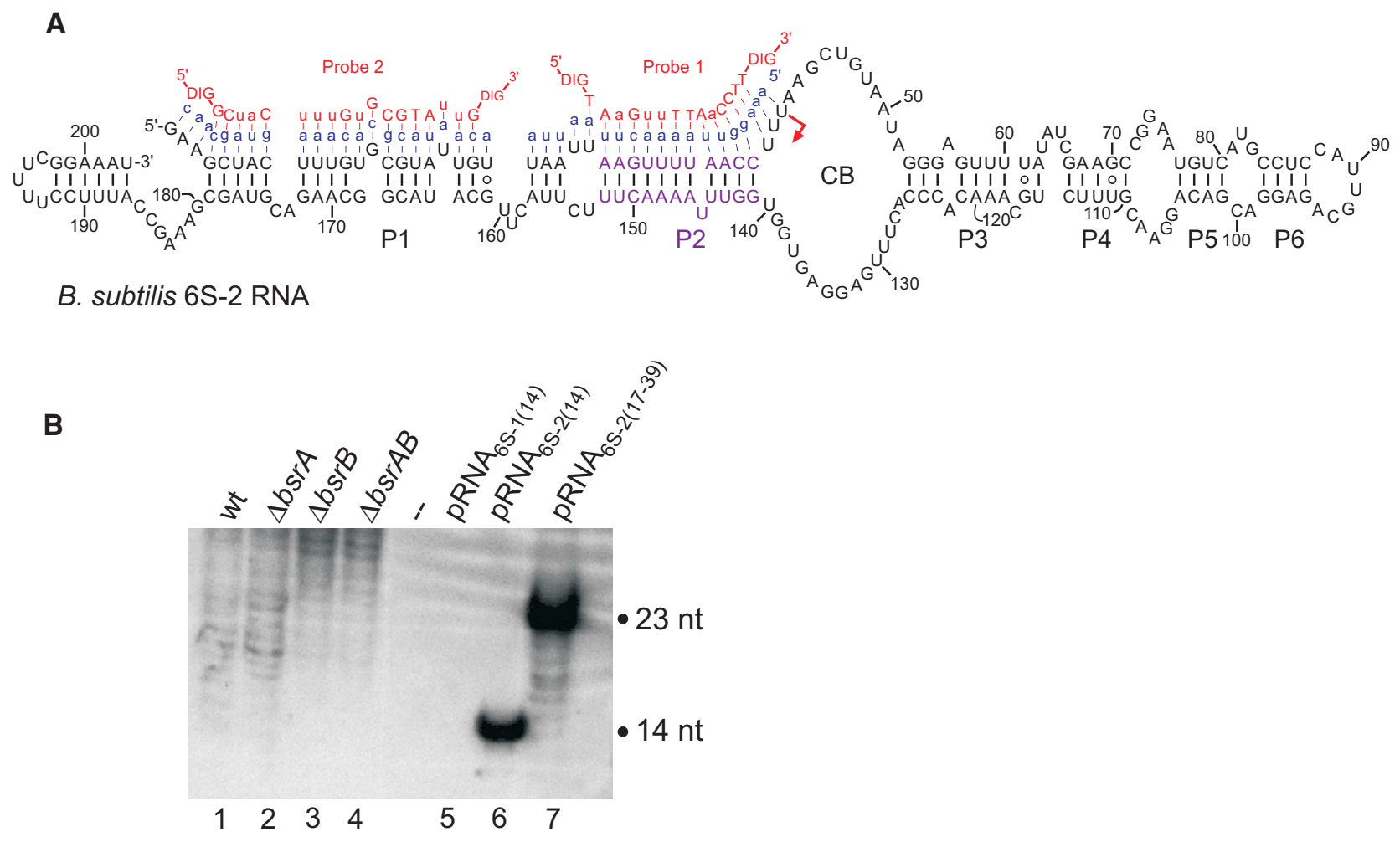

FIGURE 2. Detection of 6S-2 pRNAs by Northern blotting. (A) Secondary structure of B. subtilis 6S-2 RNA (Trotochaud and Wassarman 2005). The pRNA initiation site is indicated by the red arrow and the maximal (runoff) pRNA sequence by small blue letters along the 6S-2 RNA sequence. 6S RNA helix P2, disrupted at the beginning of pRNA synthesis, is marked in purple. CB, central bulge. The two RNA/LNA mixmer probes labeled with digoxigenin (DIG) at the $5^{\prime}$ - and $3^{\prime}$-ends are depicted as red letters on top of the pRNA sequence; capital letters indicate LNA residues and lower case letters RNA residues of the probes. $(B)$ Representative Northern blot experiment for the detection of 6S-2 pRNAs in total RNAs prepared by the TRIzol procedure from B. subtilis PY79 strains grown to mid-exponential phase $\left(\mathrm{OD}_{600}=0.7\right)$. (Lanes $\left.1-4\right)$ Total RNAs prepared from wild type (wt), $\triangle b s r A, \triangle b s r B$, and $\triangle b s r A B$ cells, respectively; (lane 5) a chemically synthesized 6S-1 pRNA 14-mer loaded as negative control; (lanes 6,7) chemically synthesized RNAs representing the first 14 nt (lane 6) or nt 17-39 (lane 7) of 6S-2 pRNAs, used as positive controls. The membrane was simultaneously incubated with both probes depicted at the top of $A$. 
A

1)

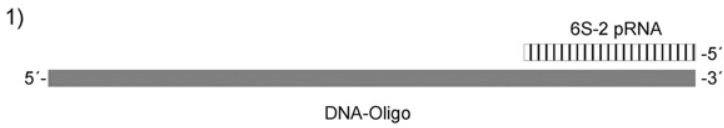

DNA-Oligo

2)

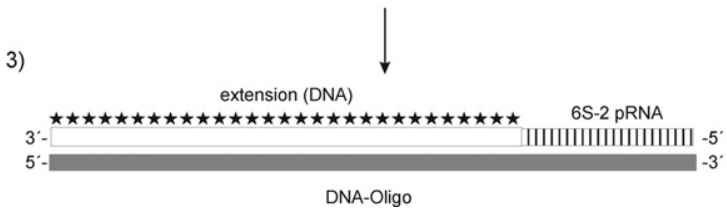

B

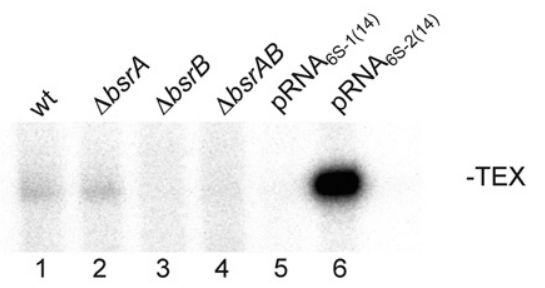

C

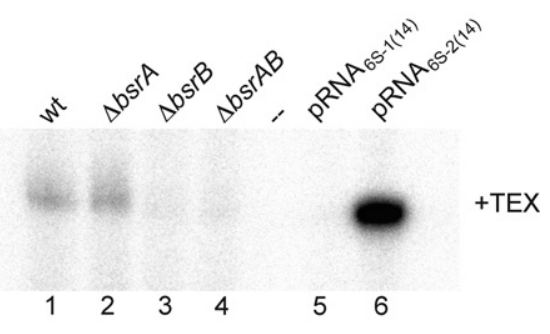

FIGURE 3. 6S-2 pRNA detection by pRNA extension on a DNA template strand. (A) Scheme of the detection setup: (1) 6S-2 pRNAs are able to hybridize to the $3^{\prime}$-end of the DNA template strand to serve as primers for elongation. (2) After addition of AMV reverse transcriptase, the pRNAs are elongated by incorporation of $\alpha^{-32} \mathrm{P}$-dNTPs. (3) The extension is limited by the length of the DNA template (72 nt). Thus, 6S-2 pRNA $3^{\prime}$ length variants are extended to a product of identical length (72 nt) resulting in one distinct band in denaturing PAA gels. (B, lanes 1-4) RNA extracts from B. subtilis wt, $\triangle b s r A, \Delta b s r B$, and $\triangle b s r A B$ cells used as primer source in the primer extension assay; (lanes 5,6$)$ chemically synthesized 6S-1 pRNA (lane 5) or 6S-2 pRNA 14-mers (lane 6) used as RNA component. ( $C$ ) As in panel $B$, except that cellular RNAs (lanes 1-4) were pretreated with TEX to degrade RNAs with $5^{\prime}$-monophosphates, thus enriching for pRNA primary transcripts with $5^{\prime}$-triphosphate termini. 6S-2 pRNA specificity of primer extension was further shown by use of a mismatch control DNA template oligonucleotide carrying three nucleotide exchanges in the $3^{\prime}$ region complementary to 6S-2 pRNAs (for details, see Materials and Methods). No specific primer extension signal was obtained in this case (data not shown).

has the ability to extend an RNA primer annealed to a DNA template strand, all pRNA length species that hybridized to the template should be elongated until the polymerase falls off the template DNA at its $5^{\prime}$-end. Thereby, the highly diverse 6S-2 pRNA length species are channeled into one single elongation product which can be detected by autoradiography after denaturing PAGE.

Using this assay, four different total cellular RNA extracts were screened for the presence of 6S-2 pRNAs, including RNA isolated from the wt, $\triangle b s r A, \Delta b s r B$, and $\triangle b s r A B$ strains. A distinct primer extension product was exclusively observed with RNA fractions from the wt and $\triangle b s r A$ strains (Fig. 3B, lanes 1,2 ). The extension product had the same gel mobility (72 nt) as in lane 6, where we added a synthetic 6S-2 pRNA 14-mer, indicating that endogenous pRNAs indeed annealed to the 3 -portion of the DNA template oligonucleotide as illustrated in Figure 3A. As control, a synthetic 14-meric 6S-1 pRNA was used as RNA component. Since no extension product was detectable here (Figure 3B, lane 5), unspecific primer annealing could be ruled out.

To further support our conclusion that cellular 6S-2 pRNA primary transcripts with $5^{\prime}$-triphosphate ends are the priming RNA species, we performed the same experiments as shown in Figure 3B, but using cellular RNA extracts pretreated with terminator $5^{\prime}$-phosphate-dependent exonuclease (TEX) before primer extension. TEX specifically degrades RNAs carrying 5'-monophosphate ends (Sharma et al.
2010) and thus enriches for primary transcripts. This primer extension experiment (Fig. 3C) showed a similar result as the one in Figure 3B, yet even with a somewhat improved signalto-background ratio. In conclusion, the primer extension assay provided the third evidence in support of 6S-2 pRNA synthesis in B. subtilis cells.

\section{DISCUSSION}

\section{S-2 RNA is a template for pRNA synthesis in exponentially growing cells}

Using Illumina-based RNA-seq, we were able to identify substantial amounts of 6S-2 pRNA reads in RNA preparations from exponentially growing $B$. subtilis cells (Table 1; Fig. 1). Detection of these pRNA reads depended on the presence of the respective 6S-2 RNA gene, supporting their identity as genuine pRNA reads. This finding, additionally supported by two other independent approaches (Figs. 2, 3), clarifies a central question in the field, i.e., how B. subtilis $\sigma^{\mathrm{A}}$-RNAP can escape from sequestration by $6 \mathrm{~S}-2$ RNA. Evidently, RNAP does so by 6S-2 RNA-directed pRNA transcription, which complements previous in vitro results demonstrating that all functional hallmarks of 6S RNAs also apply to 6S-2 RNA: The RNA (i) serves as a template for pRNA transcription, (ii) binds with similar affinity as 6S-1 RNA to $\sigma^{\mathrm{A}}$-RNAP, (iii) is capable of competitively inhibiting transcription from DNA promoters, and (iv) 
forms 6S RNA:pRNA complexes that (v) disrupt binding to $\sigma^{\mathrm{A}}$-RNAP (Burenina et al. 2014).

Only very low numbers of $6 \mathrm{~S}-2$ pRNA reads were detected in RNA libraries from stationary cells. A reverse correlation was observed for 6S-1 pRNA reads that are more abundant in stationary phase libraries (Table 1; Fig. 1). These findings are basically in line with the differential expression profiles of the 6S-1 and 6S-2 template RNAs: 6S-2 RNA peaks in exponentially growing cells and tends to thin out toward stationary phase, whereas 6S-1 RNA accumulates in stationary phase, but has low expression levels during early exponential growth (Beckmann et al. 2011). We infer from the data in Table 1 and Figure 1 that more RNAP molecules form a complex with 6S-2 RNA in early exponential phase than in stationary phase where the levels of the competing 6S-1 RNA are particularly high.

The detection of only weak 6S-2 pRNA Northern blot signals in Figure $2 \mathrm{~B}$ is not surprising, for the following reason: We previously obtained very weak Northern blot signals for 6S-1 pRNAs in late exponential/early stationary phase $\left(\mathrm{OD}_{600}=4-5\right.$; Beckmann et al. 2011), where 6S-1 RNA levels are much higher than in the RNA fractions used in Figure 2B (mid-exponential phase; $\mathrm{OD}_{600}=0.7$ ). Since roughly equal numbers of 6S-1 and 6S-2 pRNA reads were detected in RNA preparations from mid-exponential growth phase (Table 1, exponential phase, wt cells), we would not only expect very weak signals for $6 \mathrm{~S}-1$ pRNAs but also for $6 \mathrm{~S}-2$ pRNAs.

Based on Northern blots using T7 transcripts of 6S RNAs as quantitative standards, we recently estimated 6S-2 RNA levels to be roughly threefold higher than 6S-1 RNA levels during exponential phase $\left(\mathrm{OD}_{600} \sim 0.9\right.$; Hoch et al. 2015). In view of the RNA-seq data (Table 1) suggesting roughly equal numbers for 6S-1 and 6S-2 pRNAs for wt cells during exponential phase, this may be taken as evidence that $\sigma^{\mathrm{A}}$ RNAP less actively synthesizes pRNAs on 6S-2 RNA compared with 6S-1 RNA. This would be in keeping with the finding that initiation of 6S-1 pRNA transcription with GTP is more efficient than initiation of 6S-2 pRNAs with ATP (Cabrera-Ostertag et al. 2013). One should note that all considerations on 6S-1 and 6S-2 pRNA synthesis discussed here are based on the detection of pRNA steady-state levels. At present, it is unclear whether 6S-1 and 6S-2 pRNA are degraded at different rates.

The current picture is that 6S-1 and 6S-2 pRNA levels are low but measurable in exponential phase. 6S-1 pRNA levels increase and 6S-2 pRNA levels decrease when cells enter stationary phase (Table 1; Fig. 1). 6S-1 pRNA levels accumulate during extended stationary phase (death phase when optical density decreases; Beckmann et al. 2011), where 6S-2 pRNA levels are low. During early outgrowth from stationary phase, there is a burst of 6S-1 pRNA synthesis (Beckmann et al. 2011; Cavanagh et al. 2012) that largely exceeds 6S-2 pRNA synthesis at any of the conditions analyzed, in line with the notion that $6 \mathrm{~S}-1$ RNA is more intensely utilized as transcrip- tion template by B. subtilis $\sigma^{\mathrm{A}}$-RNAP than 6S-2 RNA. In view of the burst of 6S-1 pRNA synthesis during outgrowth, 6S-1 RNA may also be considered as a more dynamic regulator of RNAP function than 6S-2 RNA, at least as long as no specific conditions (e.g., stresses) are known at which 6S-2 RNA might give rise to a similar burst of pRNA synthesis. It also appears that the regulatory function of 6S-1 RNA is specifically in growth adaptation, while 6S-2 RNA may impact on other cellular functions yet to be pinpointed. Another issue is whether 6S-1 and 6S-2 RNAs have differential capacities to bind to RNAP holoenzymes with other sigma factors than $\sigma^{\mathrm{A}}$. Such a capacity could be largely excluded for E. coli 6S RNA where specific 6S RNA binding was exclusively observed with $\sigma^{70}$-RNAP, but neither with $\sigma^{\mathrm{S}}$ or $\sigma^{32}$ holoenzymes nor with core RNAP or $\sigma^{70}$ alone (Trotochaud and Wassarman 2005). However, this specificity issue needs to be investigated for the B. subtilis system.

While a 6S-2 RNA deletion resulted in no measurable growth phenotype under standard laboratory conditions (Cavanagh et al. 2012), or only in a minor phenotype under alkaline stress conditions (Hoch et al. 2015), this does not necessarily imply that 6S-2 RNA is functionally silent. We observed that deletion of the 6S-2 RNA gene leads to an up-regulation of numerous proteins involved in metabolism and stress responses, and for exponentially growing cells, this effect was stronger for a 6S-2 than a 6S-1 RNA deletion (Hoch et al. 2015). Several of the identified proteins were also upregulated in the 6S-1 RNA deletion strain (in stationary phase), suggesting that there is functional overlap between the two 6S RNAs.

\section{Differences in 6S-1 and 6S-2 pRNA length patterns and mechanistic implication}

6S-1 pRNAs are more G/C-rich than 6S-2 pRNAs. As a consequence, 6S RNA:pRNA hybrid structures are estimated to be stable enough to cause RNAP release when 6S-1 pRNAs have a length of $\geq 13 \mathrm{nt}$, whereas $6 \mathrm{~S}-2$ pRNAs have to be $\sim 20$ nt in length to attain the same hybrid stability (Burenina et al. 2014). This may imply that essentially only the longest 6S-2 pRNA transcripts (Table 1) result in persistent dissociation of 6S-2 RNA from RNAP, whereas the same function is exerted by $6 \mathrm{~S}-1$ pRNAs $\geq 13 \mathrm{nt}$. As the fraction (not necessarily the absolute number) of 6S-2 pRNAs that are close in length to runoffs largely increases in stationary phase (Table 1), a higher fraction of 6S-2 pRNA transcription cycles is predicted to lead to irreversible 6S-2 RNA:RNAP dissociation in this growth state.

We saw a trend toward higher proportions of very long pRNA transcripts (including runoff transcripts) in the case of 6S-2 RNA relative to 6S-1 RNA (Table 1). This propensity was also observed in pRNA transcriptions in vitro at lower NTP concentrations $(20 \mu \mathrm{M}$; Burenina et al. 2014, Fig. 9 therein). There is evidence that those 6S RNAs that form less rigidly rearranged structures in the central bulge (CB) 
region upon pRNA synthesis give rise to longer pRNAs. For example, a $B$. subtilis mutant 6S-1 RNA with a destabilized hairpin in the $3^{\prime}-\mathrm{CB}$ and thus increased conformational flexibility, had a lower affinity for $\sigma^{\mathrm{A}}$-RNAP and yielded a pRNA length pattern shifted to longer transcripts relative to the wt 6S-1 RNA (Beckmann et al. 2012). Likewise, in the Escherichia coli system, a 6S RNA mutant unable to form the extended hairpin in the $3^{\prime}$-CB upon pRNA synthesis yielded pRNAs of 14 and 18-28 nt in length compared to 9- and 13-mers obtained with the wt 6S RNA (Panchapakesan and Unrau 2012). Finally, for B. subtilis 6S-2 RNA, formation of a central bulge collapse (CBC) helix upon pRNA-induced disruption of helix P2 is less stable and thus less favored than in the case of 6S-1 RNA (Beckmann et al. 2012).

\section{Potential interplay of 6S-1 and 6S-2 RNA}

The RNA-seq results indicate that the expression of $6 \mathrm{~S}-1$ pRNAs increases in the absence of 6S-2 RNA (Fig. 1B, left, strains $\triangle b s r B$ and $\triangle b s r A B+A)$. In exponential phase, 18 - to 35 -fold more $6 \mathrm{~S}-1$ pRNA reads were detected than in the wt strain (blue bars in Fig. 1B, left part). For RNA samples from stationary phase cells this difference further increased to 24- to 92-fold even (red bars in Fig. 1B, left part). This observation suggested an influence of the presence of 6S-2 RNA on the utilization of 6S-1 RNA as template for pRNA transcription. We considered the possibility that the less efficient pRNA transcription on 6S-2 RNA, resulting in more effective sequestration of RNAP by this RNA, may normally restrict 6S-1 RNA access to RNAP and thus 6S-1 RNA utilization as a template for pRNA transcription. To validate this trend seen in the RNA-seq data, we performed 6S-1 pRNA-specific Northern blot analyses using total RNA extracted from the wt and mutant strains. However, with about 10 independent RNA extracts prepared from wt and $\triangle b s r B$ bacteria in parallel, either using the hot phenol or TRIzol method (Damm et al. 2015), no consistent results were obtained. With RNA prepared by the hot phenol method (as done in the RNAseq experiment), we could see higher pRNA levels for the $\Delta b s r B$ relative to the wt library in most experiments, but not all. This was also observed for total RNAs prepared by the TRIzol method enriching for small RNAs, but here only in less than half of the preparations. On the other hand, in neither RNA preparation we saw a more intense 6S-1 pRNA signal for RNA prepared from the wt compared with the $\Delta b s r B$ strain. One possibility is that the transcriptomes of $\Delta b s r B$ cell populations are less stable than those of the wt strain and often (but not always) undergo a shift manifesting as increased 6S-1 pRNA levels.

\section{Concluding remarks}

The majority of bacteria encode a single 6S RNA which, according to present knowledge, acts as a growth phase-dependent global regulator of the housekeeping RNA polymerase holoenzyme. Surprisingly, a minority of bacteria, mainly those belonging to the firmicutes but also some others like the $\gamma$-proteobacterium Legionella pneumophila, express at least two different 6S RNAs (for review, see Wehner et al. 2014; Burenina et al. 2015). In the case of B. subtilis-the major model system for the study of bacteria expressing two 6S RNA paralogs — the available data suggest differential as well as overlapping roles of 6S-1 and 6S-2 RNAs (Cavanagh et al. 2012, 2013; Cabrera-Ostertag et al. 2013; Hoch et al. 2015). Further investigations are required to better understand the biological reasons why a second 6S RNA paralog with a different expression profile has evolved in $B$. subtilis and related bacteria. This concerns the question whether 6S-2 RNA may have specialized functions under so far unidentified environmental conditions or if the RNA may affect physiological conditions that are relevant to the survival of real wild-type strains rather than the so-called laboratory "wild-type" strains, such as B. subtilis 168 or PY79. Regardless of such possibilities, we have added here an important mechanistic piece of the jigsaw by demonstrating the ability of $6 \mathrm{~S}-2$ RNA to direct pRNA synthesis in vivo as a prerequisite to release $\sigma^{\mathrm{A}}$-RNAP from its transcription block. This feature of 6S-2 RNA qualifies the RNA as an authentic 6S RNA and disfavors possible scenarios according to which 6S-2 RNA simply sequesters $\sigma^{\mathrm{A}}$-RNAP as a static inhibitor that may only be removed from RNAP by competing RNAP ligands or by RNases attacking the RNA when bound to the RNAP holoenzyme. The capacity of 6S-2 RNA to direct pRNA synthesis in vivo as a means to release RNAP equips the second 6S RNA paralog with an important dynamic functional feature specific to this type of riboregulator.

\section{MATERIALS AND METHODS}

\section{Strains and cell growth}

For total RNA isolation, exponential phase cells were prepared as follows. Single colonies were picked from LB agar plates (containing the appropriate antibiotic for selection of mutant strains) to inoculate $3 \mathrm{~mL}$ of lysogeny broth (LB) (Bertani 1951). Cultures were grown overnight at $37^{\circ} \mathrm{C}, 220 \mathrm{rpm}$, in a shaking (warm air) incubator (GFL 3033). Of note, $1 \mathrm{~mL}$ of these overnight cultures was used to inoculate $300 \mathrm{~mL} \mathrm{LB}$ medium in a $1000-\mathrm{mL}$ baffled Erlenmeyer flask. Cell growth was performed at $37^{\circ} \mathrm{C}$ at $180 \mathrm{rpm}$ in a water bath shaker (Infors AG, Infors HT, Aquatron). Growth was monitored until an $\mathrm{OD}_{600}$ between 0.6 and 0.9 (exponential growth phase) was reached. Cells were harvested by centrifugation at $4^{\circ} \mathrm{C}$ and $4000 \mathrm{rpm}$ for 15-20 min and the cell pellets were snap frozen in liquid nitrogen and stored at $-80^{\circ} \mathrm{C}$ until further use. For the construction and phenotype of the B. subtilis PY79 6S RNA deletion strains, see Hoch et al. (2015).

\section{Isolation of total RNA from Bacillus subtilis cells}

Cellular total RNA used for deep sequencing (RNA-seq) was isolated using the hot phenol method (Mattatall and Sanderson 1996; 
Beckmann et al. 2010). Cellular total RNA for Northern blotting and primer extension was prepared using the TRIzol (Ambion) method. For this purpose, pelleted B. subtilis cells were resuspended in an appropriate amount of TRIzol reagent (for a pellet deriving from 50 $\mathrm{mL}$ LB culture, $4 \mathrm{~mL}$ TRIzol were used) by vortexing and incubated for $5 \mathrm{~min}$ on ice, followed by the procedure described in Damm et al. (2015). The purity of the RNA preparation was determined by UV spectroscopy. If the $260 / 280 \mathrm{~nm}$ absorbance ratio of the RNA (dis-

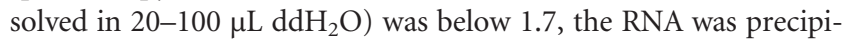
tated again using isopropanol. The quality of the RNA preparation was analyzed by $5 \%$ denaturing ( $8 \mathrm{M}$ urea) PAGE. For RNA quality, see Supplemental Figure S2.

\section{RNA-seq procedure}

Total cellular RNA was first enriched for RNAs smaller than $200 \mathrm{nt}$ using the mirVana miRNA isolation Kit (Ambion) according to the protocol supplied by the manufacturer. Then the library was enriched for primary transcripts by treatment with terminator $5^{\prime}$ phosphate-dependent exonuclease (TEX; Biozym/Epicentre), which specifically degrades RNAs carrying a 5'-monophosphate, but leaves primary transcripts carrying a triphosphate at their $5^{\prime}$-end intact. Subsequently, a 50-nt internal size marker was added to the RNA, followed by preparative $10 \%$ denaturing PAGE. RNAs with a length below $50 \mathrm{nt}$ were extracted from the gel by electro-elution, precipitated with ethanol and dissolved in RNase-free water. RNAs were subsequently treated with Tobacco Acid Pyrophosphatase (TAP, Epicentre) to convert $5^{\prime}$-triphosphates to $5^{\prime}$-monophosphates for linker ligation. Thereafter, RNA samples were poly(A)-tailed using poly(A) polymerase, and the $5^{\prime}$-adapter oligonucleotide was ligated to the $5^{\prime}$-monophosphate end. Next, first-strand cDNA synthesis was performed using an oligo(dT) primer and Moloney Murine Leukemia Virus Reverse Transcriptase (M-MLV reverse transcriptase). The generated cDNA was amplified by PCR with 17-20 cycles until a DNA yield of $\sim 20-30 \mathrm{ng} / \mu \mathrm{L}$ was reached. The PCR reaction mixtures containing the cDNA libraries were purified using the Agencourt AMPure XP Kit (Beckmann Coulter Genomics) and pooled. Library construction was carried out at vertis Biotechnologie AG (Freising, Germany). The sequencing reaction was conducted using an Illumina sequencer. Sequencing reads were cropped at the first $\operatorname{poly}(\mathrm{A})$ stretch (at least six consecutive A residues) and assigned to the respective $6 \mathrm{~S}-1$ or $6 \mathrm{~S}-2$ pRNA length species whenever the sequence matched perfectly. Given the very short length of pRNA sequences, reads with any mismatches as well as reads $<7 \mathrm{nt}$ were discarded to avoid random contamination by other very short RNAs or RNA fragments. For visualization of the mapping to both 6S RNA loci, see Figure 1A and Supplemental Figure S1.

\section{Northern blotting and hybridization}

Fifteen micrograms of total cellular RNA (prepared by the TRIzol method) or chemically synthesized control pRNAs $(0.33 \mu \mathrm{g} 6 \mathrm{~S}-1$ pRNA 14-mer, $0.33 \mu \mathrm{g}$ 6S-2 pRNA 14-mer, or $0.165 \mu \mathrm{g} 6 \mathrm{~S}-2$ pRNA nt 17-39) were mixed with 1 volume of $2 \times$ denaturing loading buffer $(0.02 \%(\mathrm{w} / \mathrm{v})$ bromophenol blue, $0.02 \%(\mathrm{w} / \mathrm{v})$ xylene cyanol, $2.6 \mathrm{M}$ urea, $66 \%(\mathrm{v} / \mathrm{v})$ formamide) and heated to $95^{\circ} \mathrm{C}$ for $2-$ $3 \mathrm{~min}$, followed by rapid cooling on ice. RNAs were separated on a $20 \%$ native PAA gel using $1 \times$ TBE as running buffer. After electrophoresis, RNAs were transferred by semidry electroblotting (over- night) onto a positively charged nylon membrane (Roche) with $\sim 0.25 \mathrm{~mA} / \mathrm{cm}^{2}$ using $0.5 \times \mathrm{TBE}$ as transfer buffer. The RNA was immobilized on the nylon membrane by crosslinking with 1-ethyl-3[3-dimethylaminopropyl]carbodiimide hydrochloride (EDC) followed by hybridization as described in Beckmann et al. (2010). In brief, after EDC crosslinking, membranes were transferred to a glass tube and incubated with $\sim 15 \mathrm{~mL}$ of "DIG Easy Hyb" (Roche) hybridization solution (prepared as indicated by manufacturer) for $2 \mathrm{~h}$ at $50^{\circ} \mathrm{C}$ under slow rotation using a Biometra CV 3 hybridization oven. After $2 \mathrm{~h}$, the hybridization solution was exchanged with another $15 \mathrm{~mL}$ of hybridization solution containing two double digoxigenin-labeled RNA/LNA mixmer probes complementary to 6S-2 pRNA, 300 pmol each (Probe 1: 5'-DIG-TAa Guu TTA aCC TTDIG-3'; Probe 2: 5' ${ }^{\prime}$-DIG-GCu aCu uuG uGC GTA uuG-DIG-3'; Ribotask; DIG indicates $5^{\prime}$ - and $3^{\prime}$-terminal digoxigenin labels, LNA residues are indicated by capital letters). Beforehand, the mixmer probes were heated to $95^{\circ} \mathrm{C}$ for $1 \mathrm{~min}$ to disrupt internal structures and probe oligomers, followed by rapid cooling on ice. After hybridization, membranes were washed as follows to remove excess amounts of the probes: $2 \times 5 \mathrm{~min}$ in $50 \mathrm{~mL}$ stringency buffer 1 ( $2 \times$ SSC, $0.1 \%$ SDS) followed by two washing steps, 15 min each, in $50 \mathrm{~mL}$ stringency buffer $2(0.1 \times$ SSC, $0.1 \%$ SDS $)$. Immunological detection was carried out using the DIG northern starter Kit (Roche) according to the manufacturer's recommendations. For RNA quality, see Supplemental Figure S2.

\section{Enrichment for primary transcripts prior to primer extension}

For removal of processed and/or degraded RNAs, the cellular RNA extracts were treated with terminator $5^{\prime}$-phosphate-dependent exonuclease (TEX; Biozym/Epicentre). TEX specifically degrades RNAs carrying a $5^{\prime}$-monophosphate, while RNAs with a $5^{\prime}$-triphosphate, a $5^{\prime}$-cap structure, or a $5^{\prime}$-hydroxyl group are not affected. The TEX treatment was performed according to the protocol recommended by the supplier (Epicentre), with minor changes. In brief, $2 \mu \mathrm{L}$ of Terminator $10 \times$ reaction buffer A (Biozym/Epicentre) were added to $10 \mu \mathrm{g}$ of total cellular RNA in a $0.2 \mathrm{~mL}$ tube and supplemented with $\mathrm{ddH}_{2} \mathrm{O}$ to a volume of $15 \mu \mathrm{L}$. Then $5 \mu \mathrm{L}$ of TEX $(1 \mathrm{U} / \mu \mathrm{L})$ were added and the reaction mixture was incubated for $90 \mathrm{~min}$ at $30^{\circ} \mathrm{C}$ in a thermocycler with a heated lid $\left(50^{\circ} \mathrm{C}\right)$ to avoid condensation. Thereafter, the reaction mixture was adjusted to a volume of $200 \mu \mathrm{L}$ with $\mathrm{ddH}_{2} \mathrm{O}$, transferred to a $1.5-\mathrm{mL}$ tube, and the reaction was terminated by addition of 1 volume of acidic phenol. The mixture was vortexed thoroughly and centrifuged for $5 \mathrm{~min}$ at maximum speed in a tabletop centrifuge $(20,000 \mathrm{~g})$ for phase separation. The aqueous phase was transferred to a new tube and the RNA was precipitated for at least $30 \mathrm{~min}$ with 1 volume of isopropanol at $-20^{\circ} \mathrm{C}$. After centrifugation at $17,000 \mathrm{~g}$ at $4^{\circ} \mathrm{C}$ for at least $30 \mathrm{~min}$, the supernatant was discarded and the RNA pellet was washed with $75 \%$ ice-cold ethanol. The RNA pellet was dried for $5 \mathrm{~min}$ in a vacuum centrifuge at $35^{\circ} \mathrm{C}$ and redissolved in $5 \mu \mathrm{L}$ dd $\mathrm{H}_{2} \mathrm{O}$.

\section{Primer extension using 6S-2 RNA-derived pRNAs as primers}

For elongation of pRNAs by AMV reverse transcriptase, a chemically synthesized DNA oligonucleotide (5'-GACGCAGTGACACCAATG 
TACTAGTAGGGTCgaagctactttgtgcgtattgttaattaagttttaaccttt-3'; small letters indicate complementarity to $6 \mathrm{~S}-2$ pRNAs, underlined nucleotides indicate the annealing region of the 6S-2 pRNA 14-mer), whose $3^{\prime}$-terminal nucleotide matched the $5^{\prime}$-terminal $6 \mathrm{~S}-2$ pRNA nucleotide, such that all 6S-2 pRNA $3^{\prime}$-length variants were able to anneal to the DNA template in the same register. A template DNA oligonucleotide with three mutations in the $3^{\prime}$-terminal part (... taagAtttTaccAtt- $3^{\prime}$ ) was used as a mismatch control. For 6S-2 pRNA extension, $2.3 \mu \mathrm{g}$ total cellular RNA prepared by the TRIzol method were mixed with the DNA template (f.c. $0.1 \mu \mathrm{M}$ ), $\alpha-{ }^{32} \mathrm{P}$ dNTPs (f.c. $83 \mathrm{nM}$ each, $3000 \mathrm{Ci} / \mathrm{mmol}$; Hartmann Analytic), $1 \times$ AMV reaction buffer (New England Biolabs) and supplemented with $\mathrm{ddH}_{2} \mathrm{O}$ to a total volume of $9.3 \mu \mathrm{L}$. The mixture was incubated for $10 \mathrm{~min}$ at $80^{\circ} \mathrm{C}$, followed by $2 \mathrm{~min}$ at $4^{\circ} \mathrm{C}$ and $5 \mathrm{~min}$ at $25^{\circ} \mathrm{C}$, then $0.7 \mu \mathrm{L}$ AMV Reverse Transcriptase (10 U/ $\mu \mathrm{L}$; New England Biolabs) were added. After an additional $15 \mathrm{~min}$ at $25^{\circ} \mathrm{C}$, the mixture was incubated for $60 \mathrm{~min}$ at $42^{\circ} \mathrm{C}$ and finally the reaction was stopped by heat inactivation of the enzyme $\left(70^{\circ} \mathrm{C}, 10 \mathrm{~min}\right)$. For reference reactions, synthetic pRNAs (f.c. $10 \mathrm{nM}$ each) instead of total cellular RNA were used: a 6S-1 pRNA 14-mer (5'-GUUCGGUCAAAA CU-3') or a 6S-2 pRNA 14-mer (5'-AAAGGUTAAAACUU-3') (both from Integrated DNA Technologies). Samples were finally mixed with 1 volume of $2 \times$ denaturing loading buffer (see above) and heated to $95^{\circ} \mathrm{C}$ for $3 \mathrm{~min}$. For the analysis of extension products, samples were subjected to denaturing 15\% PAGE and visualized by autoradiography for $0.5-2 \mathrm{~h}$ using a Fuji FLA-300 R Phosphorimager (Fujifilm).

\section{SUPPLEMENTAL MATERIAL}

Supplemental material is available for this article.

\section{ACKNOWLEDGMENTS}

This project was funded by the Deutsche Forschungsgemeinschaft (DFG) (SPP 1258 and IRTG 1384) to R.K.H.

Received December 9, 2015; accepted January 14, 2016.

\section{REFERENCES}

Ando Y, Asari S, Suzuma S, Yamane K, Nakamura K. 2002. Expression of a small RNA, BS203 RNA, from the yocI-yocJ intergenic region of Bacillus subtilis genome. FEMS Microbiol Lett 207: 29-33.

Barrick JE, Sudarsan N, Weinberg Z, Ruzzo WL, Breaker RR. 2005. 6S RNA is a widespread regulator of eubacterial RNA polymerase that resembles an open promoter. RNA 11: 774-784.

Beckmann BM, Grünweller A, Weber MHW, Hartmann RK. 2010. Northern blot detection of endogenous small RNAs ( $\sim 14 \mathrm{nt})$ in bacterial total RNA extracts. Nucleic Acids Res 38: e147.

Beckmann BM, Burenina OY, Hoch PG, Kubareva EA, Sharma CM, Hartmann RK. 2011. In vivo and in vitro analysis of 6S RNA-templated short transcripts in Bacillus subtilis. RNA Biol 8: 839-849.

Beckmann BM, Hoch PG, Marz M, Willkomm DK, Salas M, Hartmann RK. 2012. A pRNA-induced structural rearrangement triggers 6S-1 RNA release from RNA polymerase in Bacillus subtilis. EMBO J 31: 1727-1738.
Bertani G. 1951. Studies on lysogenesis. I. The mode of phage liberation by lysogenic Escherichia coli. J Bacteriol 62: 293-300.

Burenina OY, Hoch PG, Damm K, Salas M, Zatsepin TS, Lechner M, Oretskaya TS, Kubareva EA, Hartmann RK. 2014. Mechanistic comparison of Bacillus subtilis 6S-1 and 6S-2 RNAs-commonalities and differences. RNA 20: 348-359.

Burenina OY, Elkina DA, Hartmann RK, Oretskaya TS, Kubareva EA. 2015. Small noncoding 6S RNAs of bacteria. Biochemistry (Mosc) 80: $1429-1446$.

Cabrera-Ostertag IJ, Cavanagh AT, Wassarman KM. 2013. Initiating nucleotide identity determines efficiency of RNA synthesis from $6 \mathrm{~S}$ RNA templates in Bacillus subtilis but not Escherichia coli. Nucleic Acids Res 41: 7501-7511.

Cavanagh AT, Wassarman KM. 2013. 6S-1 RNA function leads to a delay in sporulation in Bacillus subtilis. J Bacteriol 195: 2079-2086.

Cavanagh AT, Sperger JM, Wassarman KM. 2012. Regulation of 6S RNA by pRNA synthesis is required for efficient recovery from stationary phase in E. coli and B. subtilis. Nucleic Acids Res 40: 22342246.

Damm K, Bach S, Müller KMH, Klug G, Burenina OY, Kubareva EA, Grünweller A, Hartmann RK. 2015. The impact of RNA isolation protocols on RNA detection by northern blotting. Methods Mol Biol 1296: 29-38.

Hoch PG, Burenina OY, Weber MHW, Elkina DA, Nesterchuk PVS, Hartmann RK, Kubareva EA. 2015. Phenotypic characterization and complementation analysis of Bacillus subtilis 6S RNA single and double deletion mutants. Biochimie 117: 87-99.

Mattatall NR, Sanderson KE. 1996. Salmonella typhimurium LT2 possesses three distinct $23 \mathrm{~S}$ rRNA intervening sequences. J Bacteriol 178: 2272-2278.

Pall GS, Codony-Servat C, Byrne J, Ritchie L, Hamilton A. 2007. Carbodiimide-mediated cross-linking of RNA to nylon membranes improves the detection of siRNA, miRNA and piRNA by northern blot. Nucleic Acids Res 35: e60.

Panchapakesan SS, Unrau PJ. 2012. E. coli 6S RNA release from RNA polymerase requires $\sigma 70$ ejection by scrunching and is orchestrated by a conserved RNA hairpin. RNA 18: 2251-2259.

Sharma CM, Hoffmann S, Darfeuille F, Reignier J, Findeiss S, Sittka A, Chabas S, Reiche K, Hackermüller J, Reinhardt R, et al. 2010. The primary transcriptome of the major human pathogen Helicobacter pylori. Nature 464: 250-255.

Steuten B, Hoch PG, Damm K, Schneider S, Köhler K, Wagner R, Hartmann RK. 2014. Regulation of transcription by 6S RNAs: insights from the Escherichia coli and Bacillus subtilis model systems. RNA Biol 11: 1-14.

Suzuma S, Asari S, Bunai K, Yoshino K, Ando Y, Kakeshita H, Fujita M, Nakamura K, Yamane K. 2002. Identification and characterization of novel small RNAs in the aspS-yrvM intergenic region of the Bacillus subtilis genome. Microbiology 148: 2591-2598.

Trotochaud AE, Wassarman KM. 2005. A highly conserved 6S RNA structure is required for regulation of transcription. Nat Struct Mol Biol 12: 313-319.

Vester B, Wengel J. 2004. LNA (locked nucleic acid): high-affinity targeting of complementary RNA and DNA. Biochemistry 43: 13233-13241.

Wassarman KM. 2002. Small RNAs in bacteria: diverse regulators of gene expression in response to environmental changes. Cell 109: 141-144.

Wassarman KM, Saecker RM. 2006. Synthesis-mediated release of a small RNA inhibitor of RNA polymerase. Science 314: 1601-1603.

Wassarman KM, Storz G. 2000. 6S RNA regulates E. coli RNA polymerase activity. Cell 101: 613-623.

Wehner S, Damm K, Hartmann RK, Marz M. 2014. Dissemination of 6S RNA among bacteria. RNA Biol 11: 1467-1478. 

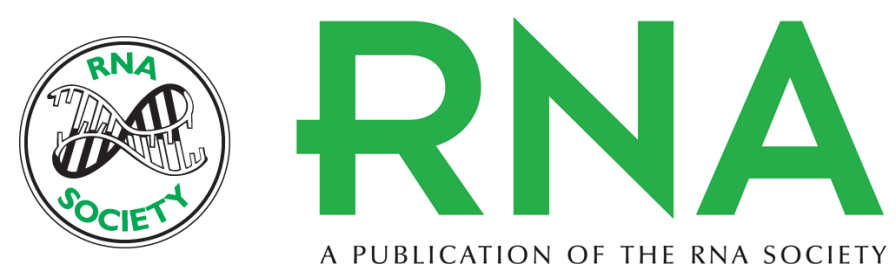

A PUBLICATION OF THE RNA SOCIETY

\section{Bacillus subtilis 6S-2 RNA serves as a template for short transcripts in vivo}

Philipp G. Hoch, Julia Schlereth, Marcus Lechner, et al.

RNA 2016 22: 614-622 originally published online February 12, 2016

Access the most recent version at doi:10.1261/rna.055616.115

\section{Supplemental http://rnajournal.cshlp.org/content/suppl/2016/01/28/rna.055616.115.DC1 Material}

References This article cites 25 articles, 8 of which can be accessed free at: http://rnajournal.cshlp.org/content/22/4/614.full.html\#ref-list-1

Creative This article is distributed exclusively by the RNA Society for the first 12 months after the Commons full-issue publication date (see http://rnajournal.cshlp.org/site/misc/terms.xhtml). After 12

License months, it is available under a Creative Commons License (Attribution-NonCommercial 4.0 International), as described at http://creativecommons.org/licenses/by-nc/4.0/.
Email Alerting Receive free email alerts when new articles cite this article - sign up in the box at the Service top right corner of the article or click here.

\section{IIII!" Providing Precise Solutions tor your research.}

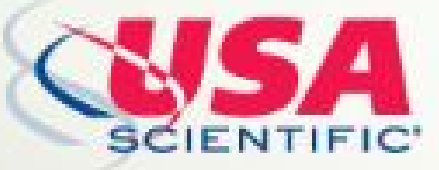

To subscribe to $R N A$ go to:

http://rnajournal.cshlp.org/subscriptions

(C) 2016 Hoch et al.; Published by Cold Spring Harbor Laboratory Press for the RNA Society 